\title{
Cambios histopatológicos en la necrosis miocárdica mediante la expresión de fibronectina
}

\section{Histopathological changes in myocardial necrosis through fibronectin expression}

\section{J. Blanco Pampín ${ }^{1}$ \\ M. Varela Gómez ${ }^{2}$ \\ JL. Román Rodríguez ${ }^{3}$ \\ ${ }^{1}$ Jefe de Servicio de \\ Patología Forense. Instituto de Medicina Legal de \\ Galicia. Santiago de \\ Compostela (A Coruña) \\ ${ }^{2}$ Médico Forense Titular. \\ Instituto de Medicina Legal \\ de Galicia. Santiago de \\ Compostela (A Coruña) \\ ${ }^{3}$ Técnico de Anatomía \\ Patológica. Instituto de Medicina Legal de Galicia. \\ Santiago de Compostela}

(A Coruña).

Correspondencia:

José Blanco Pampín

Instituto de Medicina Legal de Galicia

Servicio de Patología Forense

c/ Viena s/n, $4^{\mathrm{a}}$ planta

15705 Santiago de Compostela

(A Coruña)

E-mail: jose.blanco.pampin@usc.es

Fecha de recepción:

27.FEB.2015

Fecha de aceptación: 23.MAR.2015

\section{Resumen}

El objetivo principal del estudio ha sido la aplicación de técnicas inmunohistoquímicas para poder efectuar el diagnóstico de la isquemia miocárdica en fases precoces con un margen mayor de seguridad. Se han seleccionado casos de muerte súbita de origen cardíaco en sujetos adultos, y se ha realizado una valoración descriptiva y semicuantitativa de los haIlazgos. El diagnóstico histopatológico mediante la utilización de fibronectina por procedimientos inmunohistoquímicos ha demostrado una sensibilidad muy superior a la de las tinciones habituales. Los resultados altamente satisfactorios y la simplificación al máximo de la técnica pueden contribuir a su implantación en los laboratorios forenses y a que sea aplicada en un número importante de casos judiciales.

Palabras clave: Patología forense. Muerte súbita. Isquemia miocárdica. Diagnóstico histopatológico. Inmunohistoquímica. Fibronectina.

\section{Abstract}

The main objective of the study was the application of immunohistochemical techniques in the diagnosis of myocardial ischemia in the early stages with a greater margin of assuredness. We have selected cases of sudden cardiac death in adults, making a descriptive and semiquantitative assessment of the findings. Histopathological diagnosis by inmunohistochemical techniques using fibronectin antibodies has shown higher sensitivity than routine techniques. The satisfactory results as well as well as the simplification of the technique contributes to its implementation in forensic laboratories and application in an important number of forensic cases.

Key words: Forensic pathology. Sudden cardiac death. Myocardial ischemia. Microscopic diagnosis. Fibronectin. 


\section{Introducción}

En nuestro país, y en concreto en nuestro medio de trabajo, muchas de las autopsias médico-legales que se practican no cuentan con el apoyo de exámenes complementarios de tipo histopatológico. En muchos casos de sospecha de infarto de miocardio, el diagnóstico post mórtem se ve reducido a un nivel macroscópico, muchas veces inferido de otro tipo de lesiones presentes en el cadáver (por ejemplo, un grado considerable de arteriosclerosis coronaria) 0 basado exclusivamente en la sintomatología previa al fallecimiento y relatada de forma inexacta o errónea por los testigos, sin que exista una verdadera correlación anatomopatológica.

Dado que la mayoría de los estudios acerca de la isquemia miocárdica se han efectuado en el modelo animal y que existen escasos estudios post mórtem en corazones humanos, o están basados exclusivamente en estudios clínicos, decidimos que el trabajo debía centrar su atención en la investigación de la cardiopatía isquémica en humanos, al tratarse de un material relativamente poco estudiado y todavía menos la técnica inmunohistoquímica que hemos decidido ensayar.

La matriz extracelular cardíaca contiene un gran número de componentes fundamentales para el desarrollo cardíaco, su funcionamiento normal y la reparación del miocardio. Entre todos ellos destaca, por su importancia, la fibronectina (Fn). Se trata de una proteína con múltiples propiedades y funciones en la adhesión celular, que se encuentra en la sangre y en una variedad de tejidos como la matriz extracelular (Figura 1). La Fn es el componente clave de la matriz provisional durante la reparación de una herida ${ }^{1}$, y a menudo está elevada en los tejidos durante la remodelación tisular y la fibrosis². Otras funciones incluyen la mediación en la adhesión celular, promoviendo la migración celular y la quimiotaxis, ayudando además a regular el crecimiento celular. Posee, pues, una función de adhesión biológica y de estimulación de la formación de una matriz del colágeno ${ }^{3}$. La Fn es particularmente abundante en las vías migratorias para células embrionarias, como aquellas relacionadas con la gastrulación, la migración de la cresta neural y la migración celular del mesodermo precardíaco. Está también típicamente localizada en el tejido conectivo y en las membranas basales en el embrión (rara vez en el adulto). Los acúmulos de fibrina en las heridas cutáneas poseen también importantes cantidades de Fn, donde sirve como sustrato para las células migratorias durante la reparación tisular (tejido de granulación). La presencia de Fn en los vasos sanguíneos de corazones adultos es muy escasa, pero

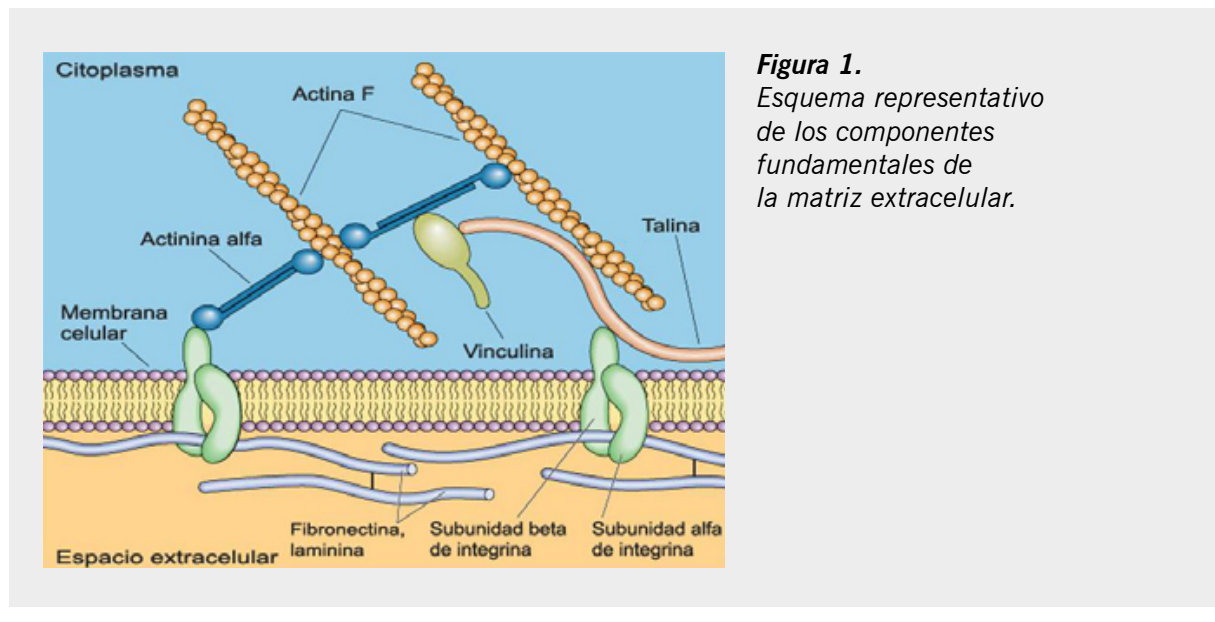

en los vasos sanguíneos de otros órganos sí hay una fuerte inmunorreactividad ${ }^{1,4}$. Se ha detectado, además, en las membranas basales de los capilares y en el endotelio arterial, en las células musculares lisas y en los fibroblastos de la adventicia, probablemente por depósito de Fn plasmática ${ }^{5,6}$.

In vitro, muchos tipos de células endoteliales sintetizan Fn, y curiosamente, en las células de las válvulas cardíacas bovinas apenas se sintetiza7. Desde el punto de vista genético, se trata de una glucoproteína codificada por un solo gen relativamente largo, con una longitud estimada de 50 kilobases, pero existente en un número variable de formas. Por una parte existe una forma denominada plasmática, presente en la sangre como una glucoproteína soluble en el plasma en una concentración de 0,3 g/l, y por otra, existe la forma celular producida por una amplia variedad de tipos celulares que la secretan y a menudo la organizan en el interior de la matriz extracelular. La Fn está compuesta por tres tipos de módulos, denominados tipos I, II y III8. Estos tres módulos proteicos básicos son usados como bloques estructurales por otras proteínas. Así, el módulo I también se encuentra en el activador tisular del plasminógeno. El tipo II es similar al de los coágulos sanguíneos y las proteínas fibrinolíticas. Finalmente, el tipo III se encuentra en la tenascina, en las moléculas de adhesión celular como la L1, y en muchas otras proteínas como unidad básica estructural. Un cierto número de factores de crecimiento y de citocinas puede regular la síntesis de $\mathrm{Fn}$, incluyendo el factor de crecimiento tumoral beta ${ }^{9}$. Los mecanismos por los cuales estos factores regulan la expresión génica permanecen aún sin esclarecer.

Molecularmente, es un monómero de peso 279.000 Da; sin embargo, la Fn se encuentra en general como un dímero unido por un puente disulfuro, o como un multímero comprimiendo las fibrillas extracelulares. 
En el plasma existe en forma de discos moleculares de unos $30 \mathrm{~nm}$ de diámetro y $2 \mathrm{~nm}$ de espesor ${ }^{10,11}$. Tanto la Fn plasmática como la celular pueden ser convenientemente incorporadas al interior de las fibrillas, pero tienden a permanecer segregadas, lo que sugiere que los ensamblados alternativos pueden ayudar a regular una organización supramolecular. Cuando se incorporan al interior de las fibrillas, estas adquieren estabilidad. La proteína ha sido muy poco estudiada en el corazón humano. Las células embrionarias cardíacas, incluyendo los miocitos cardíacos, los fibroblastos y las células endoteliales ${ }^{12,13}$, se parecen algo a otras células embrionarias ${ }^{14}$ que se transforman en Fn y se ha visto cómo, después de la embriogénesis, la Fn de las fibras cardíacas aumenta ${ }^{15}$.

Obviando las diferencias entre los anticuerpos ensayados, el trabajo que se expone está en la misma línea de investigación que el artículo publicado en el número 35 de Cuadernos de Medicina Forense ${ }^{16}$ y en sendos libros de histopatología forense editados en los Estados Unidos y en nuestro país ${ }^{17,18}$, donde se aplica el método inmunohistoquímico con diferentes anticuerpos a casos forenses de muerte súbita cardíaca de difícil resolución. Para ello hemos estudiado un total de 89 corazones humanos. Los hallazgos se han expuesto mediante una valoración descriptiva y semicuantitativa. Al mismo tiempo, se expone un procedimiento inmunohistoquímico simplificado al máximo, de cara a su futura implantación en los laboratorios forenses de histopatología.

\section{Material y método}

En el estudio realizado se ha seleccionado exclusivamente material humano compuesto de muestras procedentes de autopsias médico-legales. Se ha intentado reunir muestras pertenecientes a sujetos de todas las edades y de ambos sexos, independientemente de que a priori pudieran ser considerados individuos de riesgo, y por tanto candidatos a morir repentinamente. Es decir, la selección se ha efectuado sobre la población que fallece súbitamente y que a diario pasa por la mesa de autopsias, con el fin de reproducir con la máxima fiabilidad posible las condiciones de campo con que se enfrenta el médico forense.

El tiempo transcurrido entre el fallecimiento y la extracción de las muestras se conocía con bastante exactitud en la mayor parte de los casos, y no excedía de 16 horas. Durante este tiempo, el cadáver se mantuvo refrigerado a $4{ }^{\circ} \mathrm{C}$ en el depósito.
Al igual que han hecho otros autores, de la selección de casos se decidió excluir aquellos en los cuales se habían practicado maniobras de reanimación cardiopulmonar $^{19}$, en especial ante la posible existencia de masaje cardíaco o la inyección intracardíaca de catecolaminas o de otros fármacos, pues tales maniobras pueden inducir lesiones similares a la isquemia20,21; teniendo en cuenta también que tales maniobras pueden originar además una depleción de ciertas proteínas, así como afectar a la integridad de la permeabilidad del sarcolema y falsear los resultados con los anticuerpos que ensayamos. Pero no solo las lesiones traumáticas, como el masaje cardíaco enérgico, pueden ocasionar depleción de antígenos, sino también el efecto de la corriente eléctrica que se utiliza en las maniobras de cardioversión, así como la reperfusión tisular, que afecta de manera especial a la $\mathrm{Fn}^{22}$. Por consiguiente, fueron excluidos también del estudio los casos de pacientes ingresados en la Unidad de Cuidados Intensivos y sometidos a medidas de soporte antes del fallecimiento. En total se han estudiado 89 corazones, los cuales compusieron los siguientes grupos o categorías:

- Controles positivos: 15 casos con evidencia macroscópica de infarto de miocardio reciente (algunos de ellos documentados clínicamente).

- Controles negativos: 16 individuos con muerte rápida de etiología no cardíaca, especialmente víctimas de traumatismos craneoencefálicos en accidentes de tráfico, precipitaciones, heridas por arma de fuego, etc. Se partió de la base de considerar que, cuando una muerte tiene lugar de forma instantánea o casi instantánea, los cambios hipóxicos agonales de la fibra cardíaca no existen o bien son mínimos, constituyendo un buen control negativo.

- Casos problema: 58 casos, para cuyo estudio se clasificaron en varios grupos en función de la duración de los síntomas clínicos o pródromos (duración inferior o superior a 6 horas), y según el hallazgo anatomopatológico principal observado durante la autopsia (grado de aterosclerosis, presencia de trombosis coronaria, etc.).

Previamente se excluyeron 14 casos por distintos motivos: no disponer del número de muestras suficientes para realizar el estudio inmunohistoquímico o no estar adecuadamente fijadas, porque no eran representativas de la lesión, por encontrarse afectadas por la putrefacción o porque los resultados de la inmunohistoquímica no eran satisfactorios. Teniendo en cuenta la duración de los síntomas, establecimos dos grandes categorías: un grupo formado por aquellos casos cuya duración de síntomas fue inferior a 6 horas $(n=43)$ y otro en el que la duración era superior a 6 horas ( $n$ $=15$ ). Durante el estudio se consideraron, además, 
las grandes variables anatomopatológicas presentes en este tipo de muertes, como son la presencia de trombosis y el grado de aterosclerosis coronaria. Se realizaron secciones de tejido de $4 \mu \mathrm{m}$, que se tiñeron con hematoxilina-eosina y tricrómico de Masson para su estudio sistemático. A continuación se obtuvieron nuevas secciones para la realización de técnicas inmunohistoquímicas.

El estudio inmunohistoquímico se llevó a cabo mediante la técnica del complejo estreptavidinabiotina-peroxidasa, utilizando el anticuerpo Fibronectina (Monoclonal Dako) en dilución 1:5.000. La técnica inmunohistoquímica se realizó sobre cortes de parafina de $5 \mu \mathrm{m}$ de espesor, que se recogieron en portas tratados con 3-aminopropiltrietoxisilano (Fluka, Buchs, Suiza) diluido al $2 \%$ en acetona. Los cortes se introdujeron en una estufa de secado a una temperatura de $50{ }^{\circ} \mathrm{C}$ durante 24 horas. Tras desparafinarlos e hidratarlos, se efectuaron los siguientes pasos:

- Desenmascaramiento antigénico por calor: los cortes se trataron en tampón citrato sódico 10 $\mathrm{mM}, \mathrm{pH} 6$, en microondas a $750 \mathrm{~W}$ de potencia, haciendo primeramente dos pases de 5 minutos cada uno. Se retiraron los cortes y se dejaron enfriar en el mismo tampón a temperatura ambiente durante 20 minutos.

- Dos lavados con PBS (Phosphate Buffer Saline) durante 5 minutos cada uno y se rodeaba la muestra con Dako Pen.

- Retirada del exceso de PBS.

- A partir de aquí se procedió a la incubación del anticuerpo primario con los siguientes pasos:

- Dilución en albúmina bovina (Sigma) al 0,1\% en PBS a pH 7,5.

- Dilución del anticuerpo en la albúmina bovina anteriormente preparada.

- Incubación durante 1 hora a temperatura ambiente.

- Dos lavados con PBS a temperatura ambiente durante 5 minutos cada uno.

- Retirada del exceso de PBS.

-. Anticuerpo biotinado: incubación durante 30 minutos a temperatura ambiente, con DUET (Dako), $1.000 \mu \mathrm{l}$ de PBS $+10 \mu \mathrm{l}$ de reactivo $\mathrm{C}$ $+15 \mu \mathrm{l}$ de NGS (Normal Goat Serum, Dako).

- Dos lavados con PBS a temperatura ambiente durante 5 minutos cada uno.

- Retirada del exceso de PBS.

- Inhibición de la peroxidasa endógena con $\mathrm{H}_{2} \mathrm{O}_{2}$ al $3 \%$ durante 10 minutos a temperatura ambiente.
- Dos lavados con PBS a temperatura ambiente durante 5 minutos cada uno.

- Retirada del exceso de PBS.

- Complejo estreptavidina-biotina-peroxidasa: incubación durante 30 minutos a temperatura ambiente con DUET (Dako), $1000 \mu$ de PBS + $10 \mu$ l de reactivo $A+10 \mu$ l de reactivo $B$.

- Dos lavados con PBS a temperatura ambiente durante 5 minutos cada uno.

- Retirada del exceso de PBS.

- Tinción con diaminobencidina durante 10 minutos.

Se preparó la solución, antes de ser utilizada, del modo siguiente: 1 tableta de DAB (Merck) $+10 \mathrm{ml}$ de agua destilada. Añadir $10 \mu \mathrm{l}$ de $\mathrm{H}_{2} \mathrm{O}_{2}$ al $3 \%$.

- Después de lavar en agua destilada durante 5 minutos, se contratiñó con hematoxilina de Harris durante 30 segundos.

- Lavado con agua destilada, deshidratación, aclarado y montaje.

En todos los casos estudiados se valoraron las características macroscópicas y microscópicas convencionales. Se evaluó además el estado de los vasos intramiocárdicos (diabetes, hipertensión, enfermedad de las pequeñas arterias, etc.).

Se valoraron la positividad y la negatividad del anticuerpo empleado. Para cuantificar los resultados obtenidos, se realizó un recuento semicuantitativo. Se consideraron positivos cuando afectaban a más del $20 \%$ de las fibras en cada preparación. Se estableció el umbral del $20 \%$ teniendo en cuenta los resultados de los controles negativos. El recuento fue realizado a 400 aumentos por dos observadores, y todos los resultados se revisaron al cabo de 3 meses.

\section{Resultados y discusión}

Para el estudio de la muestra en su vertiente epidemiológica se incluyeron los controles positivos ( $n$ $=15)$ y los casos problema $(n=58)$. Para la descripción de la muestra y el análisis estadístico no se tuvieron en cuenta los controles negativos, resultando así una población total de 73 individuos. Las edades estaban comprendidas entre 25 y 94 años, con una media de 62,5 años (desviación típica: 13,5). Del total de los casos, 56 correspondieron a varones (77\%) y 17 a mujeres (23\%). La media de edad para los varones era de 61,3 años (desviación típica: 13,9), mientras que las mujeres tenían una media de 66,9 años (desviación típica: 11,6). Aproximadamente 
Figura 2.

Tejido miocárdico normal. Ausencia de fibronectina en citoplasma y núcleos (40x).

Figura 3.

Depósito de fibronectina en el endotelio de un vaso intramiocárdico (40x).

Figura 4. Inmunomarcaje positivo para Fn en una placa de ateroma coronario (40x).

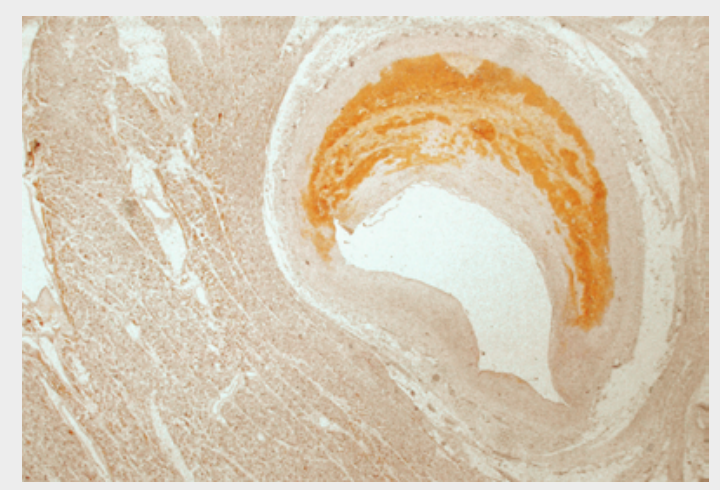

Figura 5.

Tinción positiva en miocitos isquémicos. Nítida diferenciación entre miocardio preservado y miocardio isquémico.

Preservación de estriaciones transversales y discos intercalarse (40x).

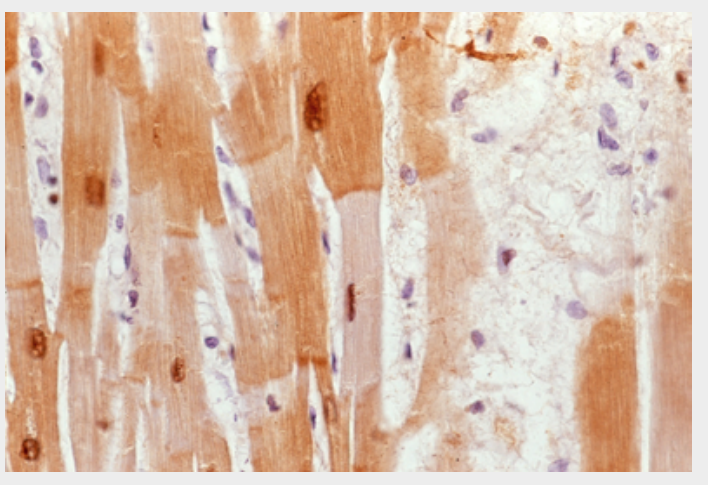

una tercera parte de los fallecimientos tuvieron lugar sin la existencia de síntomas previos relacionados, es decir, ocurrieron de forma instantánea. En otra cuarta parte este parámetro no pudo ser determinado. El síntoma más frecuente fue el dolor precordial de características anginosas; el resto de los síntomas tuvieron una escasa incidencia.

Una parte considerable de la muestra $(n=32)$ correspondía a casos con una duración de la sintomatología inferior a 1 hora; en el resto se observaron intervalos variables entre el inicio de los síntomas y el fallecimiento. Tan solo en el intervalo de 6-12 horas el número de casos fue bastante reducido. Se han identificado un total de 23 casos de trombosis coronaria $(31,5 \%)$, de los cuales 11 presentaban infarto de miocardio reconocible macroscópicamente y en 12 casos estaba ausente. Por otra parte, 9 de los casos presentaban síntomas de duración inferior a 6 horas, 1 caso superior a 6 horas y en 13 casos este dato no pudo valorarse por desconocerse el perfil de presentación. En otros 23 casos $(31,5 \%)$ pudimos identificar lesiones isquémicas que afectaban también al segmento derecho del corazón. En ningún caso se observó positividad exclusiva referida al ventrículo derecho.

Con el objetivo de valorar la sensibilidad de la técnica se utilizaron los 15 casos con infarto de miocardio macroscópicamente visible (controles positivos), y se obtuvieron resultados plenamente satisfactorios. Todos ellos mostraron positividad para este anticuerpo, por lo que la sensibilidad fue del 100\%. En otros 16 casos considerados como controles negativos (muertes muy rápidas de etiología no cardíaca) se ensayó el mismo anticuerpo, con 15 resultados negativos y uno positivo (positividad mínima). La especificidad resultante fue del 93,7\%.

En el miocito normal (Figura 2) no hemos apreciado inmunotinción para Fn en el interior de la fibra. En estos casos se comprobó su presencia exclusivamente en el endotelio de algunos vasos (Figura 3), en el intersticio celular y en las placas de ateroma (Figura 4). Se observó, además, que el mayor marcaje correspondía a los casos sin aterosclerosis y con una evolución superior a 12 horas. Por su parte, en las primeras horas de evolución, la inmunotinción entre los grupos con trombosis y aterosclerosis fue más discreta, mientras que en el intervalo de 6-12 horas no hubo positividades.

En el miocito isquémico, en especial en el situado en los bordes del infarto, se observa una intensa inmunotinción nuclear y citoplasmática, con un límite nítido entre la fibra dañada y la sana (Figura 5).

En el grupo de síntomas superiores a 6 horas, algunos casos mostraban incipientes cambios macroscópi- 
cos, caracterizados básicamente por la presencia de palidez en la zona isquémica. Otro grupo de casos mostraba una franca evolución de la necrosis, con rotura de la pared del ventrículo y hemopericardio. En los infartos de mayor evolución se observó un franco reemplazo fibroso de fibras musculares cardíacas, adoptando una distribución transmural, circunferencial o laminar, generalmente de localización subendocárdica. Todos los controles positivos marcaron alguna zona con la Fn. Por su parte, en el grupo de trombosis el fenómeno fue el contrario, es decir, el único caso que tuvimos no mostró positividad. Los casos sin aterosclerosis mostraron un comportamiento similar, y tan solo 1 caso mostró positividad en todos los cortes analizados. Así pues, desde el punto de vista global, se pudo comprobar que un $20 \%$ de la muestra fue negativa, mientras que la positividad radicó casi exclusivamente en los controles positivos. En estos casos de isquemia mantenida, la inmunotinción iba acompañada de un adelgazamiento de las fibras afectadas y un patrón de distribución intracitoplasmático de la Fn (Figura 6).

En el grupo de casos con aterosclerosis, la negatividad fue significativamente mayor que en los casos con trombosis (37,5 y $22,2 \%$, respectivamente). El grupo $\sin$ aterosclerosis y con arteriosclerosis tuvo una negatividad similar. En conjunto, se obtuvo alguna positividad en unos dos tercios de los casos estudiados. La expresión del anticuerpo fue máxima en el único control positivo de corta evolución de que dispusimos, y en general se obtuvieron positividades en diferentes grados en tres cuartas partes de las muestras analizadas.

Existe un cierto consenso respecto a la ubicación de la Fn en el tejido cardíaco normal. Diferentes estudios coinciden en señalar su localización en la membrana basal del endotelio vascular venoso, la lámina elástica de las arterias y los fibroblastos ${ }^{23-25}$. No obstante, las observaciones en situaciones de necrosis miocárdica difieren considerablemente entre sí. En general hemos visto que en las primeras fases de la isquemia las fibras afectadas presentaban una inmunotinción citoplasmática, caracterizada por el mantenimiento de las estriaciones transversales, apreciándose claramente en numerosas ocasiones los discos intercalares. Habitualmente coexistía una tinción citoplasmática junto con tinción nuclear (Figura 7). El patrón de tinción citoplasmática variaba de intensidad de una célula a otra dentro de un mismo grupo celular, aunque dentro de la misma célula se mantenía bastante uniforme (tinción más o menos homogénea), existiendo en ocasiones un claro límite entre una célula afectada y otra indemne. Los hallazgos son similares a los descritos por Shekhonin et al. ${ }^{23}$

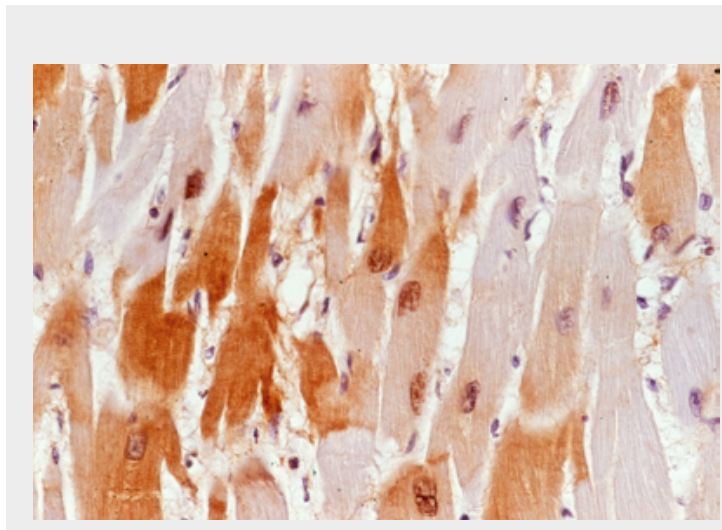

Figura 6.

Patrón de tinción intracitoplasmático sobre fibras isquémicas, algunas parcialmente afectadas con el núcleo preservado (40x).

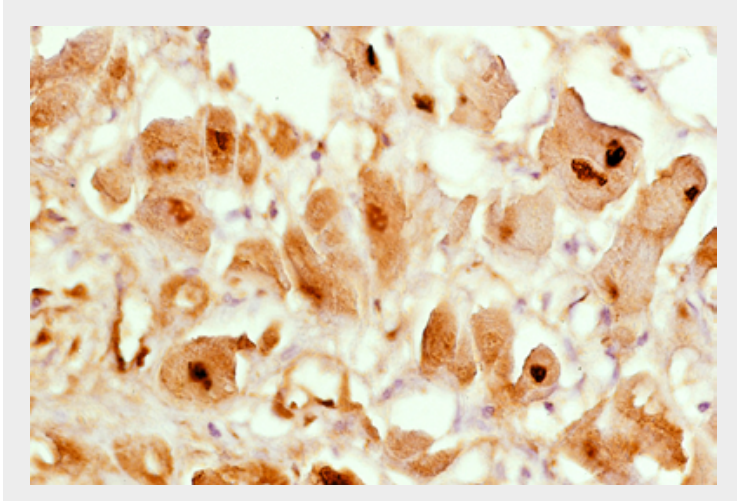

Figura 7.

Miocitos afectados por necrosis. Tinción nuclear (40x) y Knowlton et al. ${ }^{26}$ para isquemia experimental de 3 horas, y a los de Casscells et al. ${ }^{24}$ tras 4 horas de isquemia. Consideramos que esta heterogeneidad en la expresión del antígeno es una de las características más importantes de un verdadero resultado positivo.

En nuestro estudio hemos podido comprobar cómo en la utilización de la Fn resulta más fácil valorar su especificidad, por ser también una tinción nuclear. Es mucho más raro, por tanto, que haya reacciones inespecíficas en el núcleo. Por otra parte, el núcleo puede permitir una cuantificación mucho más fácil de los resultados obtenidos. Curiosamente, entre los autores consultados solo dos mostraban expreso desacuerdo respecto a la existencia de tinción nuclear $^{24,27}$.

Estudios experimentales demostraron que la Fn acumulada en la matriz extracelular penetra en el interior del miocito después de 30 minutos de oclusión coronaria. Previamente se habían descrito intervalos de 1 hora ${ }^{27,28}$ o de 3 horas $^{23}$ y 4 horas $^{24}$ en animales de experimentación. El mecanismo de introducción de la Fn se ajusta bastante bien al modelo teórico propuesto por algunos autores ${ }^{23,29}$, de tal manera que 
tras una pequeña lesión isquémica la Fn plasmática es extravasada y rodea inicialmente los miocitos isquémicos. Esta extravasación de Fn inicia el proceso de reparación tisular, dado que tiene propiedades opsónicas y quimiotácticas. Thornell et al. ${ }^{29}$ enfatizan el mayor protagonismo de la forma plasmática en la evolución del infarto y en la consiguiente reparación del daño miocárdico. La opinión expresada por este autor coincide con otros estudios que atribuyen a la Fn acumulada durante los 2-3 primeros días postinfarto un origen exclusivamente plasmático ${ }^{8,11}$ y producida por los hepatocitos ${ }^{30}$. Además, la heterogeneidad en la población de miocitos en relación con la infiltración celular podría deberse en parte a la Fn plasmática procedente del flujo colateral.

Para algunos autores, la intensidad de la tinción intracelular depende de la Fn disponible en la matriz extracelular, ya que la penetración de Fn tiene lugar primariamente en aquellas áreas de la fibra que están yuxtapuestas a los grandes depósitos de Fn en el espacio extracelular. Sin embargo, hemos visto tinciones muy positivas en el tejido intersticial (que por otra parte parece tener una distribución puramente aleatoria) sin afectación de la verdadera fibra, por lo que consideramos que este hallazgo no posee ningún significado ni guarda ninguna relación con las zonas isquémicas. Este comportamiento de los miocitos sanos abundantemente rodeados por Fn sin desarrollar ningún patrón de inmunotinción tuvo lugar sobre todo en las zonas limítrofes con el infarto, al igual que se ha visto en otros estudios publicados ${ }^{31}$.

Respecto a la distribución espacial de la inmunotinción, nuestras observaciones coinciden con las de Thornell et al. ${ }^{29}$ y las de Froen y Larsen ${ }^{32}$, de tal manera que la zona central de la región infartada presentaba una tinción más tenue que la periferia, probablemente por la degradación de la Fn en aquella zona. Por el contrario, no hemos podido confirmar la existencia de la mitad de los miocitos teñidos, tras un período estimado de isquemia de 3 horas.

De forma similar a lo observado por Ortamann et al. ${ }^{22}$, la región subendocárdica generalmente no se encontraba afectada por la necrosis. Esta observación contradice los datos ofrecidos por Larsen et al. ${ }^{31}$, quienes indican que en los bordes del infarto, en el revestimiento del pericardio y sobre todo en la superficie endocárdica, el número de miocitos teñidos oscilaba entre un $53 \%$ y un $63 \%$ después de 3 horas de isquemia. De la misma forma, nuestros datos son discordantes con los resultados obtenidos por Holmbom et al. ${ }^{33}$, quienes efectúan un trabajo experimental con cerdos y encuentran un patrón de tinción de parche irregular subendocárdico a los 30 minutos de oclusión coronaria.
Se ha especulado con la posibilidad de que la región subendocárdica permanezca intacta por estar en contacto íntimo con la sangre de la cavidad, obteniendo así un aporte de oxígeno suplementario. En cualquier caso, en esta localización (subendocárdica) hemos podido comprobar la dificultad de diferenciar los miocitos sanos de las células de Purkinje, dado que estas no se ven afectadas por la necrosis.

Aunque no hemos obtenido imágenes al microscopio electrónico, que revelen el mecanismo por el cual la Fn pierde su original ubicación en el espacio intersticial y penetra en el interior del miocito, sin embargo se ha demostrado que la penetración de $\mathrm{Fn}$ en el interior del sarcoplasma puede tener lugar a través de la superficie dañada del sarcolema ${ }^{34}$ o a través del sistema de túbulos transversales. Para Froen y Larsen $^{32}$, todas las partes de los túbulos transversales aparecen teñidas en los estadios precoces, incluyendo un gran número de vesículas, las cuales probablemente resultan de la fragmentación de los túbulos transversales de la membrana.

Estudios previos han demostrado que la membrana basal puede mantener su integridad hasta 3 horas después de la isquemia, a pesar de que el sarcolema haya sido fragmentado ${ }^{31}$. En el estudio de Froen y Larsen $^{32}$, la Fn aparece conservada en su posición a lo largo de la superficie celular después de 24 horas de isquemia, incluso en los miocitos desestructurados por la necrosis. Así, la afluencia de Fn no aparece seguir exclusivamente la extensión de la fragmentación de la superficie del sarcolema y la lámina basal, como han sugerido Shekhonin et al. ${ }^{23}$.

Ciertos autores indican que, a pesar de que el sistema de túbulos transversales se continúa con la superficie del sarcolema, cada una de esas membranas contiene una o más proteínas únicas y diferentes ${ }^{35}$, y por eso se cree que la superficie de la membrana y la membrana del sistema de túbulos transversales no son idénticas ${ }^{36}$. Diferencias en las propiedades o en la resistencia de esas membranas facilitan más o menos la penetración de la Fn a través de la membrana de los túbulos transversales.

Considerando el tamaño relativamente grande de la molécula, es obvio que la presencia de Fn intracelular sirve de evidencia de importante daño de la membrana celular; semejante criterio es aceptado como indicador de daño celular miocárdico de carácter irreversible ${ }^{29,37}$.

En los casos con menos de 6 horas de evolución clínica, el balance de este anticuerpo frente a las técnicas convencionales ha sido claramente positivo, con un $67,3 \%$ de positividades frente a un $16,3 \%$ 
en aquellas. Numerosos casos sin alteraciones morfológicas detectables con hematoxilina-eosina o con tricrómico de Masson mostraron, sin embargo, inmunopositividad con la Fn. En el grupo problema, los casos con trombosis tuvieron una tasa de negatividad $(22,2 \%)$ significativamente inferior a la de los otros dos grupos de casos con o sin arteriosclerosis (35,3\% y $35,5 \%$, respectivamente). El anticuerpo parece, pues, más efectivo en el diagnóstico de casos con trombosis coronaria, aun en ausencia de datos macroscópicos de infarto. Por el contrario, no se observaron diferencias espaciales ni en el patrón de tinción de los diferentes casos.

En la mayoría de los casos de larga evolución hemos podido comprobar que el infarto afectaba a la práctica totalidad del espesor del ventrículo, y que el patrón de tinción citoplasmático se disponía en forma de pequeñas condensaciones o pequeños grumos, formando una imagen de tipo flocular (Figura 8). Este dato concuerda con lo señalado por Holmbom et al. ${ }^{33}$, si bien su trabajo experimental realiza esta observación con un tiempo de isquemia muy inferior al nuestro (60-90 minutos).

En el grupo de evolución superior a 6 horas, todos los controles resultaron también positivos; sin embargo, el único caso con trombosis no mostró inmunopositividad. Este dato está en discordancia con lo observado en los casos de corta evolución, pero creemos que debe ser interpretado con las debidas precauciones y nos inclinamos por considerar que en los casos con trombosis la Fn también es útil. Además, hemos visto que las zonas afectadas de reperfusión (bien por proliferación colateral de capilares sanguíneos o por procesos exclusivamente fibrinolíticos) presentaban una fuerte tinción, tanto de las zonas hipereosinófilas como de las bandas de contracción, en concordancia con los hallazgos de Amberg et al. ${ }^{38}$ en infartos de una duración muy inferior a los nuestros. A pesar de estas limitaciones, la positividad mostrada por este anticuerpo fue del $80 \%$, frente a un $73,3 \%$ con hematoxilina-eosina y tricrómico de Masson. Conviene señalar que estos resultados no han podido ser comparados con ningún otro trabajo, pues en nuestro conocimiento, entre los escasísimos artículos publicados sobre Fn en infartos humanos, ninguno de ellos ha establecido esta clasificación y se han limitado a considerarlos conjuntamente.

Comparando los infartos más recientes con aquellos de mayor evolución, hemos corroborado la opinión de otros autores ${ }^{32}$, ya que después de 24 horas de isquemia la degradación afectaba también a las células de los bordes, produciéndose el consiguiente

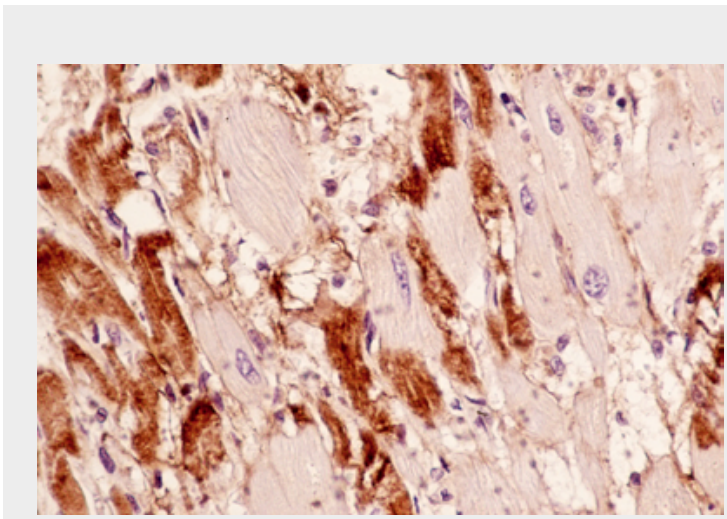

Figura 8.

Isquemia miocárdica severa mostrando una tinción con patrón flocular. Adelgazamiento de fibras, presencia de grumos intracitoplasmáticos y desaparición del núcleo (40x).

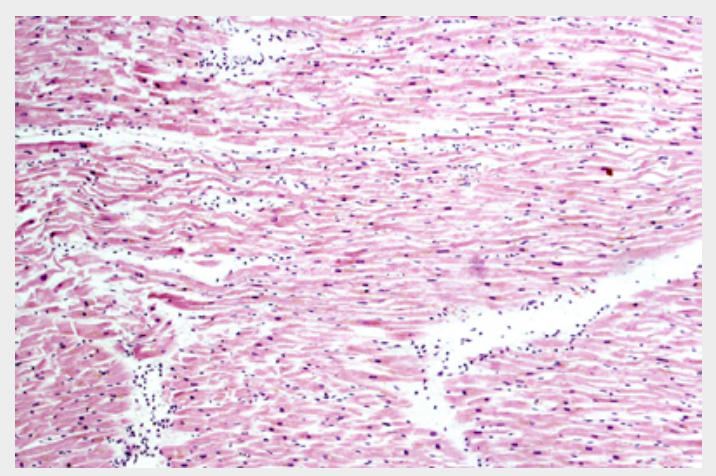

Figura 9.

Corte seriado: tejido miocárdico "normal" teñido con Hematoxilina-Eosina. Ausencia de lesiones características de isquemia (10x).

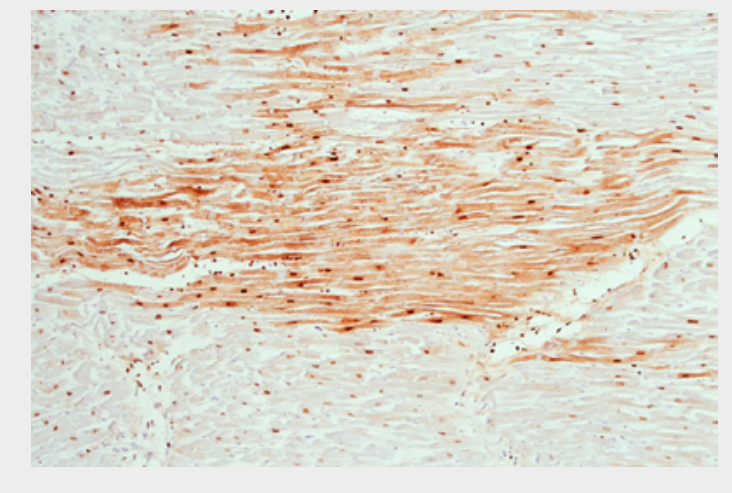

Figura 10.

Corte seriado sobre el mismo tejido. Marcaje positivo con fibronectina en una zona isquémica ( $F n, 10 x)$. Compárese con la Figura 9. descenso de la inmunotinción, y en consecuencia una disminución de las variaciones regionales.

Respecto al grado de concordancia con las técnicas convencionales, en un $28,9 \%$ de los casos ambas técnicas fueron negativas. No hubo ningún caso positivo con hematoxilina-eosina o Masson que fuera negativo para Fn. Sin embargo, casi un $40 \%$ de los casos que habían resultado negativos con hematoxilina-eosina/ Masson fueron positivos empleando Fn. Ambas técnicas coincidieron en el 31,5\% de los casos (valor del estadístico Kappa $=0,317 ; p<0,05)$. Considerando 
los resultados globales, observamos casi un $40 \%$ más de casos de positividad con este anticuerpo en corazones que habían mostrado ausencia de hallazgos o negatividad con las técnicas histológicas convencionales (Figuras 9 y 10). A la vista de estos resultados, consideramos que la utilización de este anticuerpo incrementa notablemente la seguridad diagnóstica en las necropsias.

Los autores declaran no tener ningún conflicto de intereses.

\section{Bibliografía}

1. Clark RAF, Della Pelle P, Manseau E, lanigan JM, Dvorak HF, Colvin RB. Blood vessel fibronectin increases in conjunction with endothelial cell proliferation and capillary in growth during wound healing. J Invest Dermatol. 1982;79:269-76.

2. Carsons SE. Fibronectin in health and disease. Boca Raton. Florida: CRC Press; 1989.

3. Clark R, Henson E. The molecular and cellular biology of wound repair. 2nd ed. New York: Plenum Press; 1996.

4. Stenman S, Vaheri A. Distribution of a major connective tissue protein, fibronectin, in normal human tissues. J Exp Med. 1978;147:1054-64.

5. Oh E, Pierschbacher M, Ruoslahti E. Deposition of plasma fibronectin in tissues. Proc Natl Acad Sci USA. 1978;78:3218-21.

6. Martínez-Hernández A. Electron immunohistochemistry of the extracellular matrix: an overview. Methods Enzymol. 1987;145:78-103.

7. Johnson CM, Helgison SC. Glycoproteins synthesized by cultured cardiac valve endothelial cells: unique absence of fibronectin production. Biochem Biophys Res Commun. 1988;153:46-50.

8. Kornblihtt AR, Umezawa K, Vibe-Pedersen K, Baralle FE. Primary structure of human fibronectin: differential splicing may generate at least 10 polypeptides from a single gene. EMBO J. 1985;4:1755-9.

9. Yamada KM. Fibronectin structure, functions and receptors. Curr Opin Cell Biol. 1989;1:956-63.

10. Sjoberg B, Eriksson M, Osterlund E, Pap S, Osterlund K. Solution structure of human plasma fibronectin as a function of $\mathrm{NaCl}$ concentration determined by smallangle-x-ray scattering. Eur Biophys J. 1989;17:5-11.

11. Benecky MJ, Kolvenbach CG, Wine RW, Diorio JP, Mosesson MW. Human rigid oblate structure. Biochemistry. 1990;29:3082-91.

12. Mjaatvedt CH, Lepera RL, Markwald RR. Myocardial specificity for initiating endothelial mesenchymal cell transition in embrionic chick heart correlates with a particulate distribution of fibronectin. Dev Biol. 1978;119: 59-67.
13. Linask KK, Lash JW. A role for fibronectin in the migration of avian precardiac cells: I. Dosedependent effects of fibronectin antibody. Dev Biol. 1988;129:315-23.

14. Thiery J-P, Duband J-L, Dufour S, Savagnen P, Imhof BA. Roles of fibronectins in embryogenesis. En: Mosher DF, editor. Fibronectins. San Diego: Academic Press; 1989.

15. Ahumada GG, Renard SI, Figueroa SS, Silver MH Cardiac fibronectin. Developmental distribution and quantitative comparison of possible sites of synthesis. J Mol Cell Cardiol. 1981;13:667-78.

16. Blanco Pampin J, García Rivero SA, Hinojal Fonseca R. Proteínas estructurales y mediadores de la inflamación: marcadores para el diagnóstico postmortem de la isquemia miocárdica (estudio inmunohiostoquímico). Cuad Med Forense. 2004;35:51-70.

17. Blanco Pampin J, Salguero Villadiego M. Practical manual of forensic histopathology. New York: Nova Science; 2012. págs. 173-90.

18. Salguero Villadiego M, Blanco Pampin J. Histopatología forense. Madrid: Ministerio de Justicia; 2015. págs. 253-94.

19. Hu B-J, Chen Y-Ch, Zhu J-Z. Immunohistochemical study of fibronectin for postmortem diagnosis of early myocardial infarction. Forensic Sci Int 1996;78:209-17.

20. Karch SB. Resuscitation-induced myocardial necrosis: catecholamines and defribillation. Am J Forensic Med Pathol. 1987;8:3-8.

21. Brinkmann B, Sepulchre MA, Ferchner G. The application of selected histochemical and immunohistochemical markers and procedure to the diagnosis of early myocardial damage. Int J Leg Med. 1993;106:135-41.

22. Ortmann C, Pfeiffer H, Brinkmann B. A comparative study on the immunohistochemical detection of early myocardial damage. Int J Legal. 2000;113:215-20.

23. Shekhonin BV, Guriev SB, Irgashev SHB, Kotelianski VE. Immunofluorescent identification of fibronectin and fibrinogen in experimental myocardial infarction. J Mol Cell Cardiol. 1990;22:533-41. 
24. Casscells W, Kimura H, Sánchez JA, Yu ZX, Ferrans VJ. Immunohistochemical study of fibronectin in experimental myocardial infarction. Am J Pathol. 1990;137:801-10.

25. Willems Y, Arends JW, Daemen M. Tenascin and fibronectin expression in healing human myocardial scars. J Pathol. 1996;179:321-5.

26. Knowlton AA, Connelly CM, Romo GM, Mamuya W, Apstein CS. Rapid expression of fibronectin in the rabbit heart after myocardial infarction with and without reperfusion. J Clin Invest. 1992;89:1060-8.

27. Thornell LE, Holmbom B, Eriksson A, Reiz S, Marklund $S$, Näslund U. Enzyme and immunohistochemical assessment of myocardial damage after ischemia and reperfusion in a closed-chest pig model. Histochemistry. 1992;98:341-53.

28. Thornell LE. Plasma fibronectin visualed by immunostaining - a reliable morphologic marker for myocardial damage. J Mol Cell Cardiol. 1988;20(Suppl V): 32.

29. Thornell LE, Eriksson A, Holmbom B, Johansson $B$, Näslund $U$. Fibronectin and laminin related myocardial damage and repair. J Mol Cell Cardiol. $1991 ; 23($ Suppl V):S13.

30. Tamkum JW, Hynes RO. Plasma fibronectin is synthesized and secreted by hepatocytes. J Biol Chem. 1983;258:4641-7.

31. Larsen TH, Saetersdal T, Grong K. The ultrastructure of the myocyte in different regions of experimental infarcts in the cat heart. Res Exp Med. 1986;186:295-306
32. Froen JF, Larsen TH. Fibronectin penetration into heart myocytes subjected to experimental ischemia by coronary artery ligation. Acta Anat. 1995;152:119-26.

33. Holmbom B, Näslund $U$, Eriksson A, Virtanen I, Thornell L-E. Comparison of triphenyltetrazolium chloride (TTC) staining versus detection of fibronectin in experimental myocardial infarction. Histochemistry. 1993;99:265-75.

34. Greve G, Rotevatn S, Svendby K, Grong K. Early morphologic changes in cat heart muscle cells after acute coronary artery occlusion. Am J Pathol. 1990;136:273-83.

35. Jörgensen AO, Arnold W, Shen AC, Yuan S, Gaver $\mathrm{M}$, Campbell KP. Identification of novel proteins unique to either transverse tubules (TS28) or the sarcolema (SL50) in rabbit skeletal muscle. J Cell Biol. 1990;110:1173-85.

36. Saetersdal T, Larsen T, Rotevant S, Dalen H, Scheie P. Fibronectin and laminin in transverse tubules of cardiac myocytes studied by laser confocal microscopy and immunohistochemistry. Histochemistry. 1992;98:73-80.

37. Reimer KA, Jennings RB. Myocardial ischemia, hypoxia, and infarction. En: Fozzard HA, Haber E, Jennings RB, Katz AM, Morgan HE, editores. The heart and cardiovascular system. 2nd ed. New York: Raven Press; 1992. págs. 1875-973.

38. Amberg R, Gudat F, Mihatsch MJ. Immunomorphology of myocardial infarction. En: Somogori E, Sotonyi P, editores. Sudden cardiac death. Budapest: De. Semmelweis Kiadó; 1994. págs. 56-67. 